$\begin{array}{ll} & \text { Etnográfica } \\ \text { etnográfica } & \text { Revista do Centro em Rede de Investigação em }\end{array}$

Antropologia

vol. $20(3) \mid 2016$

Vol. 20 (3)

\title{
Do uso e cobertura da terra à experiência etnográfica: croquis e imagens de satélite na Amazônia rural brasileira
}

From land use and cover change to ethnographic experience: between sketches and satellite images of the Brazilian rural Amazon

Roberto Donato da Silva Júnior, Álvaro de Oliveira D'Antona e Anthony D. Cak

\section{OpenEdition}

Journals

\section{Edição electrónica}

URL: https://journals.openedition.org/etnografica/4676

DOI: 10.4000/etnografica.4676

ISSN: 2182-2891

\section{Editora}

Centro em Rede de Investigação em Antropologia

Edição impressa

Data de publição: 1 outubro 2016

Paginação: 583-606

ISSN: 0873-6561

Refêrencia eletrónica

Roberto Donato da Silva Júnior, Álvaro de Oliveira D'Antona e Anthony D. Cak, «Do uso e cobertura da terra à experiência etnográfica: croquis e imagens de satélite na Amazônia rural brasileira»,

Etnográfica [Online], vol. 20 (3) | 2016, posto online no dia 27 novembro 2016, consultado o 10

fevereiro 2022. URL: http://journals.openedition.org/etnografica/4676 ; DOI: https://doi.org/10.4000/ etnografica.4676

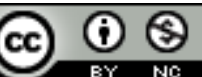

Etnográfica is licensed under a Creative Commons Attribution-NonCommercial 4.0 International License. 


\section{Do uso e cobertura da terra à experiência etnográfica: croquis e imagens de satélite na Amazônia rural brasileira}

\section{Roberto Donato da Silva Júnior,} Álvaro de Oliveira D'Antona

e Anthony D. Cak

O objetivo do artigo é explorar as potencialidades de uma experiência etnográfica entre duas perspectivas de uso e cobertura da terra em assentamentos agrícolas na Amazônia: a técnico-científica, com a produção/classificação de imagens de satélite; e a nativa, com a produção/classificação de desenhos de agricultores. Apresenta-se a pesquisa, as similitudes/discrepâncias entre as perspectivas, a experiência etnográfica entre os protagonistas e as potencialidades de uma análise equivalente entre diferentes percepções da espacialidade. Resultam três ordens de contribuições: uma, referente à equivalência de perspectivas nos estudos do uso e cobertura da terra; outra, sobre o exercício etnográfico na interseccionalidade afetivo-intelectiva; e, por fim, a identificação de uma perspectiva diagonal em movimento como expressão de espacialidade dos agricultores produzida na experiência etnográfica.

PALAVRAS-CHAVE: croquis, etnografia, experiência etnográfica, uso e cobertura da terra, sensoriamento remoto.

From land use and cover change to ethnographic experience: between sketches and satellite images of the Brazilian rural Amazon - The objective of this work is to explore two perspectives on land use and land cover change (LULC) in agricultural settlements of the Amazon region within an ethnographic experience: a "technical-scientific" view that defines LULC from afar using remote sensing techniques (classification and analysis of satellite imagery), and a "local" perspective that defines LULC by local farmers and residents using participatory sketch maps. This paper summarizes research results and the ethnographic experiences through which these perspectives may be formed, especially similarities and differences among the two. The analysis and results are divided into three views: one in which these perspectives are given equivalency across LULC studies; another describing the ethnographic experience according to an affective-intellectual intersectionality; and, finally, one that identifies a diagonally-shifting perspective, described as an expression of the spatial understanding of farmers produced through the ethnographic experience.

KEYWORDS: sketch, ethnography, ethnographic experience, land use and land cover change, remote sensing. 
SILVA JÚNIOR, Roberto Donato da (roberto.junior@fca.unicamp.br) - Faculdade de Ciências Aplicadas, Universidade Estadual de Campinas, Brasil.

D’ANTONA, Álvaro de Oliveira (alvaro.dantona@fca.unicamp.br) - Faculdade de Ciências Aplicadas, Universidade Estadual de Campinas, Brasil.

CAK, Anthony D. (anthony.cak@asrc.cuny.edu) - Environmental Sciences Initiative, CUNY Advanced Science Research Center, USA.

\section{INTRODUÇÃO}

Um processo de valorização de diferentes formas de produção e apreensão de paisagens vem ocorrendo na antropologia há, pelo menos, 30 anos. Acompanhando e problematizando uma tendência geral de fortalecimento da imagem como um instrumento de validação científica, essa valorização tem se orientado à contramão dos processos de obscurecimento das "marcas sociais" produtoras de mapeamentos. No que se refere à Amazônia, é possível observar diferentes motivações para a adesão a esta tendência. Algumas delas se agregam à "nova cartografia social", que pretende "[...] analisar os processos diferenciados de territorialização hoje em pauta na Amazônia, e sua relação com a emergência de identidades coletivas objetivadas em movimentos sociais" (Almeida 2013: 28). Outras têm se expressado por uma orientação ecológico-cultural, articulando, por exemplo, dinâmicas demográficas, uso e cobertura do solo e os efeitos das mudanças ambientais globais (Batistella, Moran e Alves 2008). Essas perspectivas se fundamentam em uma ampla utilização de técnicas de sensoriamento remoto aliadas a metodologias qualitativas, adotadas para dar voz às configurações sociais constitutivas do ambiente amazônico. As preferências, no entanto, são patentes: enquanto, na primeira, o recurso tecnocientífico está ao serviço de protagonismo político das "identidades coletivas", na segunda, as "vozes sociais" tendem a ser colocadas como "recurso de aperfeiçoamento" da interseção entre variáveis, inclusive sociais, que compõem o complexus ambiental: "Without a social scientist as part of the team, culturally important dimensions of land cover may quite possibly be overlooked by scientists who bring a nonlocal or purely remote point of view to the analysis of the data" (Moran e Brondizio 1998: 97).

Aliando-se aos esforços de superação dessas antinomias, o artigo se abre a uma reflexão sobre a aparente incongruência (ou desencontro) entre: (a) uma perspectiva "tecnocientífica", que incorpora a tecnologia de sensoriamento remoto em suas análises a partir de duas imagens de satélite em um período de três anos (2005 Landsat ETM+ image, e 2008 Landsat TM image); e (b) uma perspectiva "local", capturada através de desenhos produzidos em visitas e entrevistas com pequenos produtores rurais que vivem em propriedades ao 
longo da Rodovia Transamazônica, no estado do Pará, Brasil. Como explicar as diferenças de abordagem que possibilitam as duas perspectivas?

O desencontro se manifesta em dois momentos da pesquisa: na sobreposição de imagens e desenhos com auxílio do Sistema de Informações Geográficas (GIS), o que permitiu observar as convergências e discrepâncias de classificação de áreas de uso e ocupação; e na constatação, pelos pesquisadores, de que as informações obtidas pelos desenhos expressam mais que a possibilidade de confirmação da veracidade dos dados obtidos através das imagens de satélite.

Diante disso, nosso esforço foi no sentido de - a partir de metodologias próprias aos estudos sobre as mudanças no uso e na cobertura da terra (UCT ou, em inglês, land use and cover change, LUCC) - potencializar a interpretação dos modelos classificatórios advindos das duas perspectivas em direção a um entendimento da alteridade paisagística. O reconhecimento, por parte da equipe, de que a elaboração dos croquis implicava em uma situação bastante rica de produção de espacialidade em interação com pesquisadores e imagens, levou a três inquietações fundamentais. Como agricultores e agricultoras transpõem uma percepção paisagística "horizontal" - ou seja, produzida ao nível do "chão" - para uma perspectiva "vertical" - ou seja, pelo "alto" -, tal como expresso nas imagens e exigido na confecção dos croquis? ${ }^{1}$ Como, nessa transposição, foi possível produzir e manter a grande diversidade classificatória de usos/coberturas nos desenhos? E, por fim, como e porque a classificação nativa apresenta um grau minucioso de especificação de estratos de paisagem que geralmente não são apreensíveis na imagem de satélite? Esses questionamentos nos levaram, inevitavelmente, à reflexão etnográfica. Partindo do princípio de que esta se constitui, não em um ato "de conhecimento do outro, mas [em] conhecimento sobre o outro, com o outro" (Florêncio 2012: 624), a opção foi a de explorar a experiência etnográfica como superação da obsessão pela "pertinência" de uma ou outra perspectiva, a partir do entendimento dessa experiência como recurso de "explicitação" das condições de razoabilidade perceptiva dos agricultores e agricultoras.

Para atender estas demandas, o texto (1) descreve a pesquisa com ênfase nos resultados da sobreposição das imagens e dos desenhos sobre uso e cobertura do solo; depois, (2) tendo como ponto de partida as inquietações geradas pelos diferentes diálogos estabelecidos na pesquisa, o artigo se lança a buscar referências sobre a questão da descrição e experiência etnográfica; que, por sua vez, possibilitaram (3) uma análise das condições de produção da espacialidade dos agricultores; por fim, (4) o artigo explora as derivações conceituais do

I Neste trabalho, utilizamos o termo "horizontalidade" para indicar o vetor de perspectiva pelo qual agricultores envolvidos na pesquisa constituem sua percepção de paisagem desde o "chão"; e verticalidade para indicar o vetor de perspectiva pelo qual cientistas e técnicos envolvidos na pesquisa constituem sua percepção da paisagem desde o "alto". 
trajeto seguido e advoga a convivência entre a abordagem etnográfica e outras perspectivas teórico-metodológicas.

\section{SOBREPONDO CROQUIS A IMAGENS DE SATÉLITE}

A integração de imagens de satélite e desenhos produzidos com agricultores foi parte de um amplo estudo sobre mudanças no uso e na cobertura da terra em uma área de colonização no estado do Pará, na Amazônia Brasileira. Por iniciativa do Anthropological Center for Training and Research on Global Environmental Change, da Indiana University (ACT-IU), os estudos se iniciaram no final dos anos 1990, se estendendo até o início dos anos $2010 .{ }^{2}$ A área de estudo, entre a sede do município de Altamira e a de Uruará, possui 3916 lotes rurais em aproximadamente 403 mil hectares ao longo da Rodovia Transamazônica (BR-230) e suas vias secundárias (localmente chamadas de "travessões"). Tal área é parte de um projeto de colonização iniciado nos anos 1970 pelo Instituto Nacional de Colonização e Reforma Agrária (INCRA), no contexto das políticas federais de ocupação e desenvolvimento da Amazônia (Moran 1981).

No final dos anos 1990, visitas e entrevistas foram realizadas em um subconjunto de 402 lotes selecionados, de modo a garantir uma distribuição espacial representativa de toda a área de estudo (McCracken et al. 1999). Entre junho e setembro de 2005, realizou-se nova pesquisa de campo para retorno a tais estabelecimentos (Vanwey, D’Antona e Brondizio 2007). Os dados apresentados neste artigo decorrem dessa segunda experiência de campo.

Realizadas por uma equipe de pesquisadores do ACT apoiados por entrevistadores da região estudada, as incursões às propriedades duraram de duas horas, aproximadamente, a alguns dias, levando-se em conta que propriedades com várias casas e com arranjos de uso da terra mais complexos exigiam diversas visitas para aplicação de questionários, conversas com os moradores e caminhadas pelo estabelecimento para registro de coordenadas, por aparelho de GPS (Global Positioning System).

Os instrumentos de pesquisa incluíam questionários sobre sociodemografia, produção e história do uso e cobertura da terra no lote. Pesquisadores, dotados de cadernos de campo e gravadores, buscavam maior aproximação e diálogo com os moradores, de modo a aprofundar o entendimento das dinâmicas estudadas. De especial interesse para o presente artigo, o uso do formulário para o desenho da propriedade (croqui) significava um momento marcante em cada

2 O projeto "Amazonian Deforestation and the Structure of Households" iniciou-se com apoio dos National Institutes of Health (NIH - US Department of Health and Human Services) em 1997 (ver $<$ http://projectreporter.nih.gov/project_info_history.cfm?aid=7910666\&icde $=0>$, última consulta em outubro de 2016). 
contato com os nossos interlocutores, ao permitir o diálogo instigante entre os envolvidos.

\section{Produzindo croquis: primeiro diálogo}

Em uma folha A4, o formulário do croqui foi definido a partir das dimensões predominantes dos lotes na Transamazônica: 100 ha em retângulos de $500 \mathrm{~m} \times 2000 \mathrm{~m}$ ou $400 \mathrm{~m} \times 2500 \mathrm{~m}$, dependendo da localização com relação à Rodovia Transamazônica e seus travessões. Nele constavam elementos impressos para auxiliar na padronização das informações registradas por distintos entrevistadores. Para facilitar a comparação entre os croquis, elementos gráficos auxiliavam na definição da escala (dimensões do lote) e na orientação do desenho do lote na folha em função do seu posicionamento relativamente a elementos como rodovias e cursos de água. Além disso, foi definida uma lista de símbolos comuns para representar o repertório de elementos usualmente encontrados nas propriedades (por exemplo, estradas, caminhos, casas, barracões/depósitos), de tal modo que um mesmo tipo de elemento tivesse a mesma representação em todos os croquis. Para o preenchimento, um protocolo geral foi definido de maneira a que todos os entrevistados pudessem refinar as informações sobre o posicionamento dos elementos (infraestruturas, usos e coberturas da terra) relatados pelos interlocutores. As informações relatadas eram complementadas pelo registro de algumas coordenadas dos limites do lote junto à estrada principal (a "frente" do lote), das casas existentes e, quando pertinente, de porções com usos e coberturas da terra (D'Antona, Cak e Vanwey 2008).

No campo, os entrevistados usavam o formulário para motivar o diálogo com os moradores. Ainda que os questionários fossem direcionados aos "chefes" (homens e mulheres) de cada casa existente na propriedade, o desenho do lote se constituía em um momento que mobilizava todos os residentes, os quais geralmente se interessavam pelos mapas com imagens de satélite. Conforme compreendiam o material trazido pelos pesquisadores (mapas e imagens de satélite), passavam a expressar seus próprios conhecimentos sobre o uso e cobertura da terra na região e a auxiliar na montagem do croqui de seus lotes. Como regra, o desenho era feito pelo entrevistador com orientação e validação dos moradores. Simultaneamente, os interlocutores se valiam de outros suportes como, por exemplo, uma vareta tirada de um galho de árvore com a qual sulcavam o chão para rascunhar o croqui. Mais raramente, um ou outro entrevistado assumia o lápis e desenhava no próprio formulário juntamente com o entrevistador (D'Antona, Cak e Nascimento 2008).

Originalmente pensada como um instrumento de campo para auxiliar o preenchimento de tabelas sobre usos e cobertura da terra nos estabelecimentos visitados e para, depois do campo (no laboratório), melhorar a classificação de imagens de satélite oferecendo um vasto leque de coordenadas associadas a 
usos e a coberturas da terra específicos (D’Antona, Cak e Silva Júnior 2011), a experiência de produzir os croquis revelou uma sucessão de encontros que estimulam as análises aqui propostas. Para além do desenho - o objeto dos encontros -, a construção do croqui constituiu-se no elemento catalizador de diálogos. O "contato" subjetivo mais rico, no qual entrevistadores e entrevistados trocavam informações e experiências, tornou possível recuperar a história da vida no lote. Não apenas auxiliou a memória, como também fez ver nexos entre usos, coberturas da terra, práticas e valores com um nível de detalhamento (e de envolvimento) bastante superior ao que se pode obter através de questionários, por exemplo. Sendo assim, a relevância desloca-se do desenho, o resultado, para a interação, o processo (figura 1).

Nesse sentido, a confecção dos desenhos configurou-se em uma experiência mobilizadora (Lombardi 2013) em, pelo menos, dois níveis de socialidade. O primeiro, em torno das famílias que, para alimentarem o entrevistador com as informações necessárias à confecção dos croquis, entregavam-se a um exercício de re-conhecimento da historicidade dos seus próprios processos de uso e ocupação do solo dos lotes. Aqui, emergiram os procedimentos de associação entre momento/forma de uso/ocupação e situação/organização familiar, no

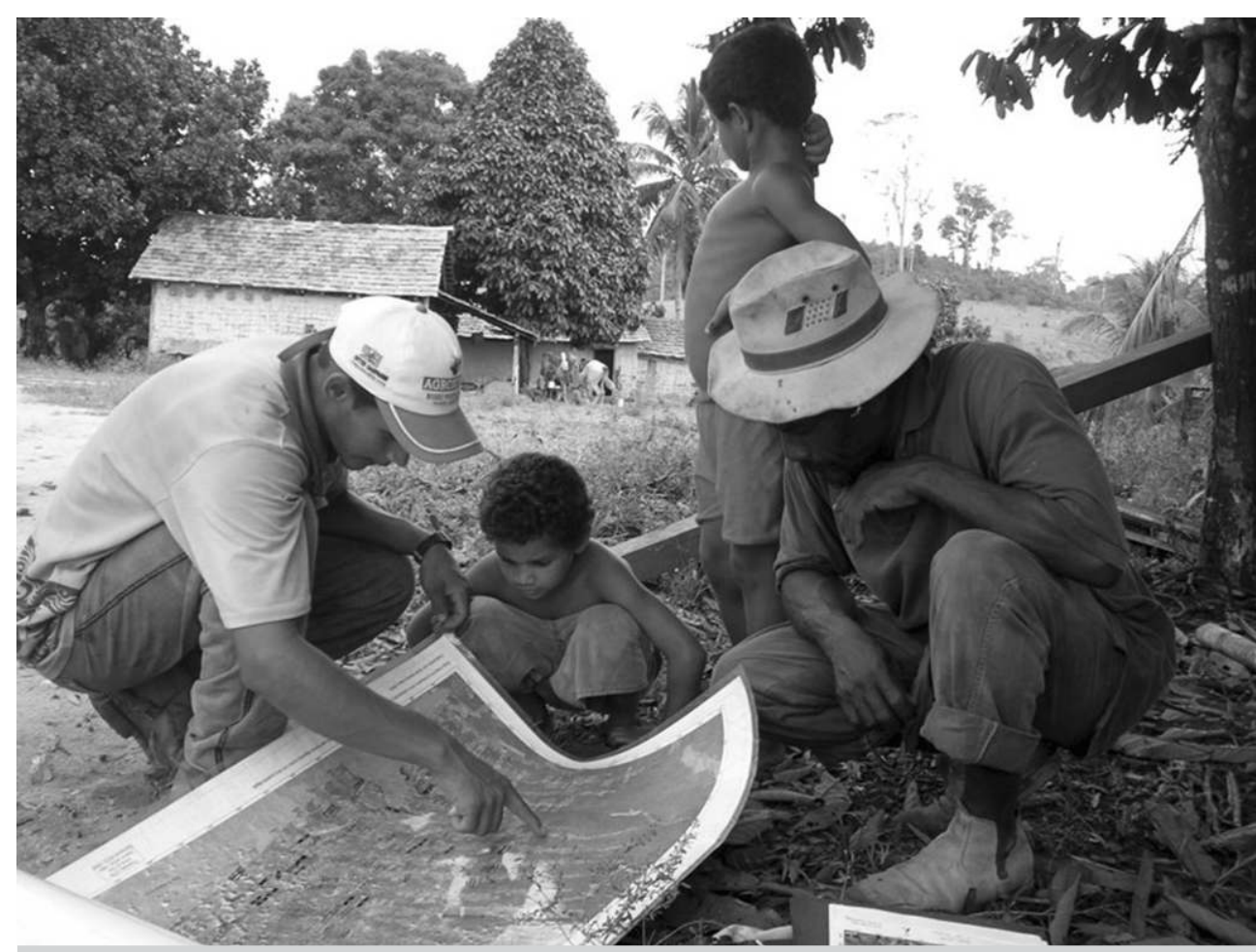

Figura 1 - O encontro. À esquerda, um membro da equipe de pesquisa em diálogo com uma família agricultora. Propriedade rural na Rodovia Transamazônica, Pará, 2005. 
que se refere tanto à situação econômica da família em dado período de ocupação do lote, quanto à dinâmica de estruturação das relações de parentesco implicada na edificação da espacialidade: a ocupação de um trecho do lote por um filho que casou; a construção de uma casa e de um roçado em local estratégico para o seu escoamento; o início de um novo plantio articulado à esperança de superação de um momento de crise econômica; o conjunto de decisões para a derrubada de uma área de floresta; o escrutínio sobre a qualidade do solo; a expectativa de valorização de um determinado cultivo no mercado e as decisões em torno da mão de obra disponível na família. Tudo isso atravessado por memórias e reminiscências articuladas a uma linguagem corporal específica, às imagens rabiscadas no ar ou no chão, ou nos entreolhares de cumplicidade em torno de uma lembrança (Lombardi 2013).

No segundo nível essas experiências possibilitaram o entendimento por parte dos entrevistadores de que os agricultores apresentavam uma forma particular de classificação de imagens. As regras de conformação do desenho estimulavam o envolvimento familiar na formulação dos croquis, a partir de um processo complexo e negociado em torno do que era, para eles, relevante de ser representado. Nesse sentido, foi possível observar que a identificação das áreas de uso, as histórias de constituição familiar e a periodização econômica geralmente se apresentavam em articulação no processo de identificação e marcação dos polígonos nos croquis. Assim, tornou-se explicitado aos participantes da pesquisa que a identificação de uma área de uso no croqui possuía uma expressiva densidade sócio-histórica.

Por decorrência desses dois processos, a questão em torno do enquadramento perspectivo utilizado pelos agricultores foi ganhando espaço, podendo ser sinteticamente aglutinada nos seguintes termos: de que forma uma espacialidade produzida "ao nível do chão" poderia ser transposta para uma perspectiva "vista pelo alto", sem perder, contudo, a referida densidade sócio-histórica que a produziu?

\section{Croquis e imagens de satélite: segundo diálogo}

A partir dessa experiência de pesquisa, os croquis foram conduzidos a um segundo tipo de diálogo, através de sua justaposição à classificação da cobertura da terra produzida pelos pesquisadores a partir das imagens de satélite. O exercício visou usar os dados de campo para superar a motivação clássica e pragmática de melhorar a classificação das imagens de satélite. Alternativamente, pretendemos contrapor o sistema classificatório científico adotado em análises de sensoriamento remoto à perspectiva local dos moradores, ambos integrados no meio usualmente empregado para a expressão de análises espaciais: um Sistema de Informação Geográfica (SIG).

Dentre os 402 croquis feitos em campo, $37 \mathrm{I}$ foram considerados adequados em relação aos princípios norteadores da produção dos desenhos. Depois de 

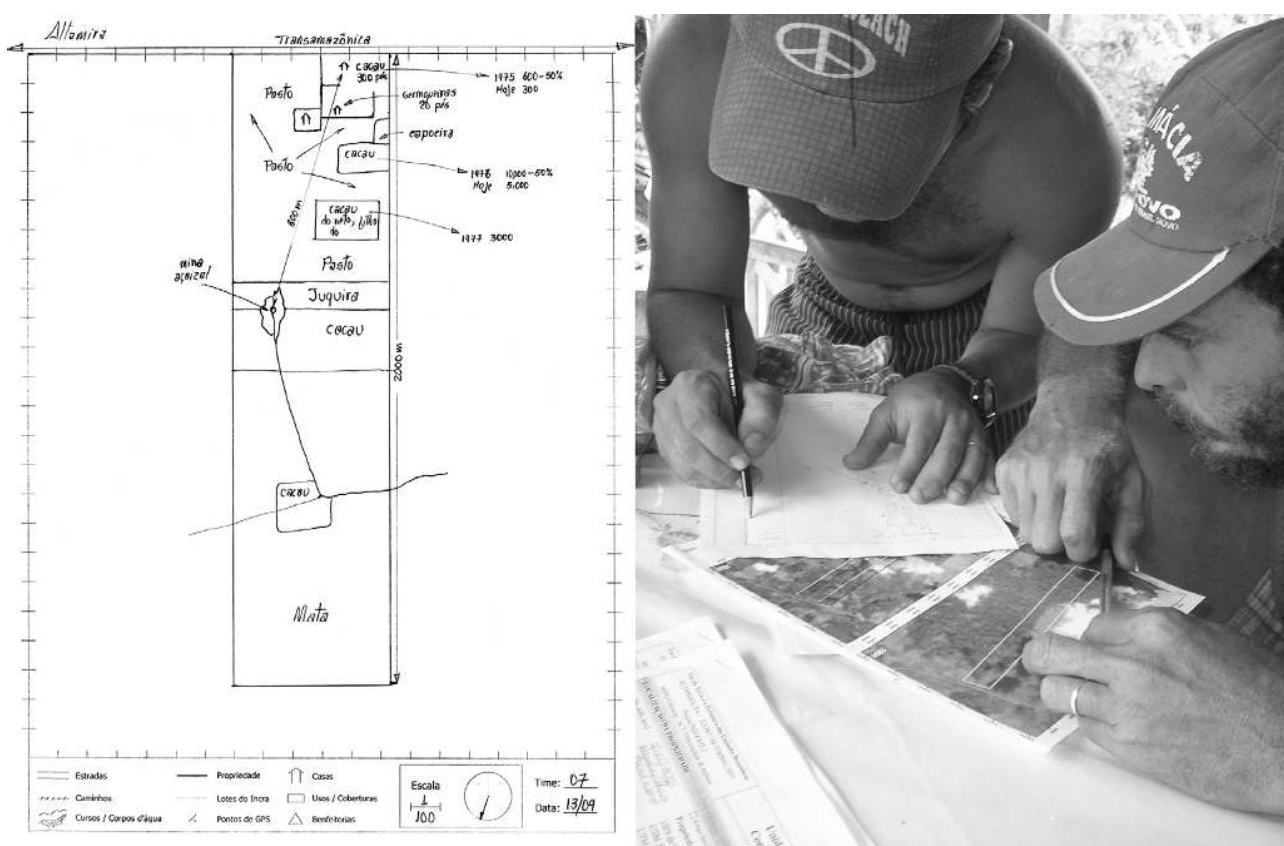

Figura 2 - Um croqui. À esquerda, um croqui de uma propriedade rural; à direita, registro fotográfico de um tipo de interação durante a elaboração de um croqui. Propriedade rural na Rodovia Transamazônica, Pará, 2005.

digitalizados, os croquis foram georreferenciados no ArcGIS 9.0 (ESRI, Redlands, CA). Como os limites das propriedades são regulares e se apresentavam em escala nos croquis, foi possível orientá-los no SIG conforme os limites dos lotes correspondentes na grade do INCRA (D’Antona, Cak e Silva Júnior 2011). O georreferenciamento com base na grade do INCRA - e não em imagens de satélite, como se poderia supor - garante que a classificação obtida pelos croquis não esteja subordinada àquela gerada pela classificação da imagem de satélite. A independência das duas classificações permite que sejam comparadas e evita o problema conceitual - e recorrente em análises de sensoriamento remoto da primazia dos dados obtidos a partir das imagens sobre os dados de campo. A figura 3 sintetiza o processo de sobreposição das duas fontes de dados.

Em um projeto do software ArcGIS, a imagem de satélite classificada (1) e os croquis digitalizados e georreferenciados conforme a grade de lotes do INCRA (2) foram sobrepostos. Os croquis foram vetorizados (3) de tal modo que tanto os limites dos lotes quanto os limites de cada uso da terra nos lotes fossem transformados em polígonos que permitem o cruzamento das classificações nas duas fontes de dados.

Durante o processo, foram descartados os croquis que não apresentavam limites precisos com relação à grade do INCRA e aqueles croquis de proprieda- 


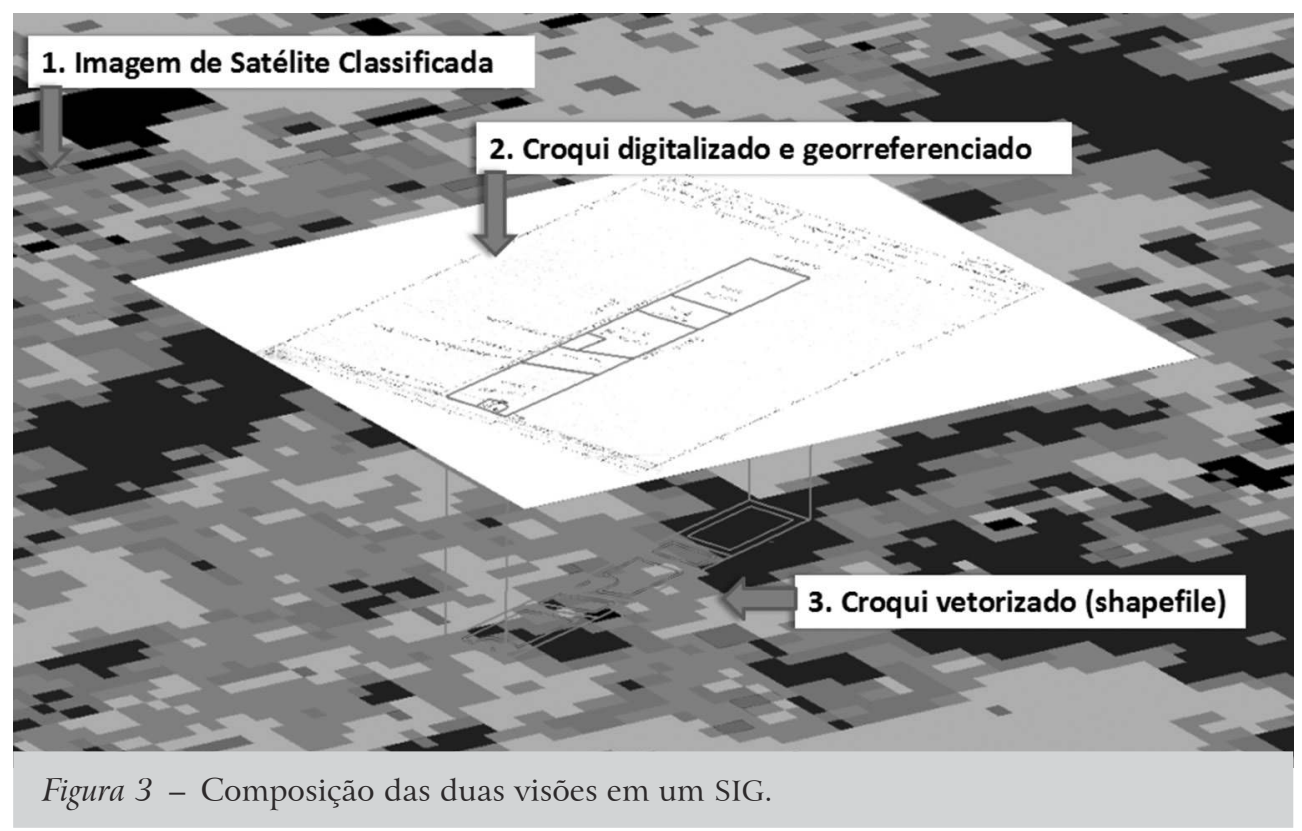

des que não apresentavam variedade de classes de uso e cobertura da terra. O processo de depuração definiu um grupo de 207 propriedades a respeito das quais foram identificados 249 diferentes termos que os moradores utilizam em referência principalmente a tipos de uso da terra (por exemplo, "cacau antigo"; "pasto sujo"; "capoeira"). Como alguns dos termos são variações de um mesmo tipo de uso/cobertura da terra, os 249 termos foram agregados em um sistema com 50 classes não redundantes.

Para este artigo, foi selecionada uma amostra aleatória de 104 lotes dentre os 207 croquis mencionados. A amostragem foi estratificada de tal modo que os lotes selecionados respeitassem a distribuição das coberturas da terra em toda a área de estudo. No SIG, os polígonos com os usos/coberturas foram sobrepostos à imagem de satélite Landsat 7 ETM+ de 2005 corrigida e classificada em nove categorias de cobertura da terra. A informação foi extraída de tal modo que se pudesse comparar as duas classificações.

Neste processo de adequação das imagens e croquis para a sobreposição, a questão da irredutibilidade das classificações se impôs de forma bastante interessante. Na transposição da espacialidade "ao nível do chão" (uso) para a "vista pelo alto" (cobertura), além da manutenção da densidade sócio-histórica expressa nos croquis, preservou-se a diversidade classificatória, mesmo diante do esforço dos operadores do SIG para promoverem a redução das classes identificadas ao limite mínimo oferecido pelo princípio da não redundância. Assim, partindo do entendimento de que a classificação dos agricultores e agricultoras se constitui do "uso para a cobertura" da terra, diversamente da 
construída pelo técnico - que vai da "cobertura para o uso" da terra (Fisher, Comber e Wadsworth 2005) -, como se produz do "chão" um entendimento tão rico da cobertura pelo "alto"?

\section{Uma matriz de correspondências}

A sobreposição das informações dos dois sistemas classificatórios permitiu, portanto, compará-los espacialmente. O que cada perspectiva tem a dizer? Em que concordam e em que divergem? Para a comparação, definimos uma "matriz de correspondências" contendo as 50 categorias de uso da terra (dos croquis) e as nove de cobertura da terra (da imagem). No cruzamento dos dois sistemas classificatórios, atribuímos os valores $-1,0$ ou 1 para: correspondências esperadas ( 1 ), aceitáveis $(0)$ ou inesperadas $(-1)$. O quadro 1 , a seguir, contém um fragmento da matriz original, para exemplificar o trabalho realizado.

\section{Quadro I}

Fragmento da matriz de correspondências

Croquis
$\begin{aligned} & \text { Solo } \\ & \text { Sulturas anuais }\end{aligned}$
$\begin{aligned} & \text { Solo } \\ & \text { Pasto }\end{aligned}$

Por exemplo, o cruzamento da categoria "floresta" nos croquis e na imagem de satélite foi definido com valor l quando verificada uma correspondência esperada entre os dois sistemas classificatórios. O cruzamento da categoria "pasto" nos croquis com SSl (sucessão secundária 1) na imagem de satélite foi marcado com o valor 0 , quando havia uma correspondência aceitável, porém sujeita a "discrepâncias" de classificação entre a imagem e os croquis - uma área em regeneração florestal pode estar em uso como pasto. Contudo, a sucessão secundária expressa uma composição de vegetação distinta da 
normalmente identificada como pastagens. No cruzamento da categoria "solo" (terra nua/exposta) nos croquis com a de "floresta" nas imagens de satélite (e vice-versa) foi marcada como - 1 a correspondência sujeita a algum tipo de "discrepância".

A matriz foi aplicada às informações de uso e cobertura da terra extraídas dos croquis e das imagens para a obtenção das áreas, em hectares, relativas a cada cruzamento. Em aproximadamente $58 \%$ da área mapeada verificou-se correspondências esperadas; em aproximadamente 17\% da área, correspondências aceitáveis; enquanto que em cerca de $25 \%$ da área as categorias identificadas nos croquis e na imagem apresentam correspondências inesperadas. Quase metade da área com correspondências inesperadas é identificada como "pasto"; as porções em regeneração (SS1, SS2 ou SS3) equivalem a quase um quarto da área com correspondências inesperadas. Tal resultado advém não somente da predominância destes dois tipos de cobertura na área de estudo, mas também da diversidade de usos e nomenclaturas atribuídas pelos moradores a feições que se apresentam de forma bastante agregada (simplificada) em classificações de imagem de satélite.

Áreas com "floresta” e áreas com "pasto" são aquelas com maior correspondência esperada. Aproximadamente $65 \%$ de toda a área identificada como "pasto" nos croquis corresponde ao "pasto" identificado na imagem de satélite. Pouco mais de $77 \%$ das áreas identificadas como "floresta" nos croquis (incluindo áreas antigas de regeneração florestal) correspondem a "floresta" na imagem de satélite. As características dessas coberturas são mais facilmente identificadas nas imagens e descritas pelos entrevistados, além de cobrirem porções mais extensas nas propriedades, o que pode facilitar seu registro em ambas as fontes.

Por outro lado, usos e coberturas com maior variabilidade na estrutura e na densidade da vegetação (por exemplo, agrofloresta, sucessão secundária, culturas perenes) apresentam menor correspondência esperada. Categorias de sucessão secundária (áreas em regeneração) apresentam o maior percentual de correspondência inesperada (60\%). Culturas anuais, agroflorestas e culturas perenes identificadas nos croquis aparecem logo a seguir, com, respectivamente, 59\%, 54\% e 49\% de correspondência inesperada com a classificação da imagem de satélite. Curiosamente, são as categorias mais relevantes para o entendimento das várias dinâmicas familiares e de seus lotes rurais - apesar de a imagem de satélite não as explicitar.

Plantações de cacau identificadas nos croquis apresentam 37\% de correspondência esperada, 36\% de correspondência aceitável e 27\% de correspondência inesperada com a imagem classificada. O nível relativamente baixo de correspondência esperada expressa a dificuldade em se classificar plantações de cacau e sistemas agroflorestais maduros em uma imagem de satélite e também a variedade de condições (tempo de cultivo e estrutura das árvores, por 
exemplo) que levam áreas identificadas nos croquis como cultivadas com cacau a corresponderem a classes como floresta, SS3, SS2, SS1 e até mesmo pasto nas imagens de satélite.

Interpretar as correspondências esperadas como acertos (concordância) dos dois meios utilizados parece óbvio. Contudo, como abordamos a seguir, julgamos inadequado considerar as correspondências aceitáveis e as inesperadas como decorrências de erros dos instrumentos de registro das informações e das operações realizadas, sobretudo no que diz respeito aos usos e significados dos croquis. Para avançar na reflexão, preferimos considerar as discrepâncias como desacordos que informam sobre sistemas (formas de ver) específicos e distintos.

\section{Discrepâncias e imprecisões?}

Conforme anteriormente indicado, as informações dos croquis e das imagens de satélite correspondem ao esperado na maior parte dos casos. Contudo, algumas classes de uso/cobertura da terra apresentam maior correspondência que outras. Vários níveis de erro podem estar contribuindo para as discrepâncias encontradas entre as duas fontes de dados. Dentre eles: imprecisões na produção dos croquis (no uso da escala, na delimitação das propriedades, na capacidade de comunicação do entrevistador com seus interlocutores) e erros na incorporação dos croquis ao SIG, como distorções causadas pelo georreferenciamento. Em nossas análises, adotamos estratégias para limitar tais ocorrências, inclusive com a seleção dos melhores croquis para incorporação ao SIG.

Os erros podem estar associados também a características da imagem (resolução do Landsat) e sua classificação. Podem decorrer de problemas na justaposição dos dois formatos de dados (polígonos e píxeis), ainda que tenhamos adotado medidas para reduzir problemas decorrentes de desajustes entre os limites dos polígonos de uso da terra (dos croquis) e os píxeis da imagem de satélite.

Sem desprezar os eventuais problemas decorrentes da imprecisão das fontes e processos adotados, é mais pertinente aprofundar a reflexão sobre as duas formas específicas de percepção de usos e coberturas da terra, conforme sintetiza o quadro 2.

Nota-se o predomínio de pastos e florestas na área de estudo, com o qual croquis e imagens concordam. Porções com certos usos agrícolas (desde culturas anuais até agrofloresta) não são percebidas na classificação das imagens mas podem ser localizadas através dos croquis. Contrariando a visão convencional, há menor perda de informação nos croquis que na imagem de satélite - sujeita à cobertura de nuvens que impedem o registro.

As discrepâncias entre croquis e imagens de satélite em áreas com relevância socioeconômica já foi notada na literatura. Uma porção descrita como estando em uso pelo produtor rural pode estar classificada como sucessão secundária 
Quadro 2

Classificações de uso/cobertura da terra nos croquis e nas imagens de satélite

\begin{tabular}{|c|c|c|}
\hline \multirow[t]{2}{*}{$\begin{array}{c}\text { Classes } \\
\text { de uso/cobertura }\end{array}$} & \multicolumn{2}{|c|}{$\begin{array}{c}\text { Percentual de uso } \\
\text { e cobertura nas proprie- } \\
\text { dades avaliadas }\end{array}$} \\
\hline & Croquis & Imagem \\
\hline Solo & 0,25 & 0,33 \\
\hline Pasto & 52,46 & 44,59 \\
\hline Anuais & 0,52 & - \\
\hline Pomar & 0,27 & - \\
\hline Perenes & 1,31 & - \\
\hline Cacau & 8,85 & - \\
\hline Agrofloresta & 0,02 & - \\
\hline $\begin{array}{l}\text { Outros usos/ } \\
\text { /coberturas }\end{array}$ & 0,36 & 0,98 \\
\hline SS & 9,28 & 16,98 \\
\hline Floresta & 26,58 & 32,50 \\
\hline \multirow[t]{2}{*}{ Sem informação } & 0,10 & 4,62 \\
\hline & 100,00 & 100,00 \\
\hline $\begin{array}{l}\text { categorias identificad } \\
\text { satélite foram padron } \\
\text { uso e cobertura da te } \\
\text { verifica nas proprieda }\end{array}$ & $\begin{array}{l}\text { hos croquis } \\
\text { das nesse sis } \\
\text { que dá cont } \\
\text { avaliadas. }\end{array}$ & de 11 classes \\
\hline
\end{tabular}

(em repouso, em regeneração florestal) em uma imagem de satélite, em uma evidente contradição (e.g., Moran et al. 1994). Além disso, termos utilizados pelos produtores rurais para qualificar determinados usos da terra (por exemplo, "sujo" e "limpo", para adjetivar o pasto; "antigo" e "novo" para o cultivo de cacau) tornam o sistema classificatório local mais rico em detalhes do que as classificações "técnicas", distantes e usualmente pautadas por descrições mais gerais (por exemplo, "pasto"). Contudo, as descrições mais detalhadas podem acabar por limitar a correspondência entre croquis e imagens de satélite e, consequentemente, aquela entre os dados de surveys e os de imagens de satélite (e.g., Romney, Kimball e Batchelder 1987; Moran et al. 1994; Rindfuss e Stern 1998; Castro et al. 2002).

O cultivo de cacau constitui-se em caso de especial interesse para a reflexão sobre as discrepâncias e sobre o potencial de se dar

voz à perspectiva local. O cacau representa um cultivo de grande importância socioeconômica, posto que gera maior renda e empregos em maior número do que outras práticas (Browder, Wynne e Pedlowski 2005). Plantações de cacau são também importantes em termos ecológicos. Ao longo dos anos, restauram a estrutura vegetal e mantêm a fertilidade do solo, prevenindo a perda de nutrientes que ocorre em outros sistemas, como nas pastagens (Schroth et al. 2001). Diferentes culturas e árvores podem ser consorciadas ao longo do ciclo de vida do cacau, incluindo o café, a banana e a mandioca em estágios iniciais (Browder, Wynne e Pedlowski 2005). Por sua relevância, sua correta identificação deveria ser uma prioridade nos estudos sobre dinâmicas socioambientais. No entanto, plantações de cacau têm sido um dos usos indevidamente classificados em análises baseadas em surveys e imagens de satélite - meios que geralmente classificam áreas de cacau como se fossem de sucessão secundária e, até mesmo, floresta (e.g., Moran et al. 1994). 
Em nosso trabalho, a perspectiva local permite identificar o cacau com relativo sucesso, na medida em que os croquis revelam os diferentes estágios de crescimento do cultivo, desde fases iniciais ("cacau novo", com um ou dois anos de cultivo) até estágios avançados de cultivo, com 20 anos de plantio, por exemplo. Essas duas áreas mencionadas no exemplo estariam, na imagem de satélite, agregadas a um mesmo tipo de classificação, obscurecendo a percepção de dois tipos de destinações econômico-ecológicas relevantes. Similar raciocínio se pode aplicar a outros usos, como as culturas anuais (as roças) e pequenos pomares que se prolongam a partir das casas dos moradores e que dificilmente são detectáveis na classificação de imagens de satélite. Tais usos, não raramente, ocupam áreas geralmente menores do que a de um píxel da imagem do Landsat $(30 \mathrm{~m} \times 30 \mathrm{~m})$.

Mesmo sendo usualmente considerada como um sistema mais objetivo e preciso, a classificação de uma imagem de satélite não permite perceber ocorrências importantes para a economia familiar. Os croquis, supostamente menos precisos no posicionamento e dimensionamento das áreas, se revelam mais sensíveis e ricos. A perspectiva local pode oferecer descrições ricas na escala em que os processos classificatórios das imagens encontram grandes limitações, justamente nas coberturas de terra onde a variabilidade de usos se coloca em riqueza de possibilidades. Ou seja, as constatações apontam que as discrepâncias não devem ser confundidas com "erro", posto que os croquis "veem" na escala na qual as imagens se tornam míopes.

Como o olhar local produz esse estrato "médio" de configuração da paisagem de forma tão acurada? Um exemplo típico - e significativamente recorrente do tipo de interação que emergiu durante a pesquisa - pode servir como ponto de partida para o desenvolvimento das repostas que procuramos. Relativamente comum no trabalho de campo era a descoberta, por parte dos entrevistadores, daquilo que transbordava relativamente à imagem de satélite. Levando consigo as imagens de satélite do lote, a tentação de tomar o papel como "documento oficial" e "retrato da realidade" era grande, principalmente no início do período em campo. Sob essa valoração, bastaria ao entrevistador enquadrar (ou direcionar) as respostas do entrevistado ao que estava pré-classificado na imagem. No entanto, estabelecida a interlocução com agricultores e agricultoras, esse posicionamento tornava-se insustentável.

Foi justamente o que se passou na aplicação da pesquisa na pequena propriedade de D. Maria. Viúva, lidava ela mesma com as tarefas normalmente atribuídas aos homens, como a roça, e aquelas que cabem às mulheres, como os cuidados com o pomar e com a horta, ambas situadas junto à casa principal, como se fosse uma extensão de seu quintal. Sua narrativa das dinâmicas de uso, impregnada de memórias, dava sentido à história do uso da terra no lote e às estratégias adotadas ao longo do tempo, de forma mais clara, viva, do que aquela que se poderia obter convencionalmente em um survey. O que era ali 
descrito como atividades cotidianas e usos da terra não correspondia ao que o entrevistador supunha existir olhando só para as imagens de satélite. Estas não eram suficientes para capturar as pequenas roças para subsistência, geralmente aquelas próximas das casas (lugares de muitas histórias e referências), ou os pequenos pomares, criadouros de aves e pequenos animais, uma vez que cada píxel das imagens geradas pelo sensor do satélite Landsat representava uma área maior do que a ocupada pelos referidos usos. Mais que isso: a imagem - expressão da visão do alto - não tinha condições de expressar os sentidos só apreensíveis deslocando-se os entrevistadores ao nível do chão, ou seja, ao olhar horizontal e indexado por fragmentos de memória familiar. Guiados pelas trajetórias sulcadas no ar pelas mãos de D. Maria, os entrevistadores tinham a possibilidade de apreender a densidade significativa de processos de demarcação experiencial da paisagem ali produzida.

De modo inverso, o olhar de D. Maria foi instado pelo entrevistador a deslocar-se da descrição horizontalizada de seu lote para a imagem de satélite. Tendo esta como elemento de contraponto e referência, a elaboração do desenho se aproximava a um processo de "sobreclassificação", de forma pormenorizada e distintiva, do que estava homogeneizado pela dimensão possível do píxel. Assim, no trânsito entre as duas referências (a localização de usos/coberturas na paisagem e a disposição do lote em uma perspectiva vertical) é que se deu a classificação nativa expressa no croqui.

Este breve exemplo expressa a demanda explicativa que, partindo da produção de dados no âmbito de estudos de uso e cobertura da terra, nos leva à reflexão etnográfica. Se foi possível produzir uma condição sólida de equivalência entre as duas perspectivas em questão, trata-se, agora, de explicitar o "como" emergiu um modelo diferencial de produção de espacialidade até aqui não previsto no estatuto atribuído ao ponto de vista local. Como a teoria etnográfica pode auxiliar na resolução deste questionamento?

\section{ETNOGRAFIA E PRODUÇÃO DE PAISAGENS}

A descrição etnográfica tem sido reconhecida como o instrumento metodológico capaz de garantir narrativas e intepretações "totalizantes" (Tylor 2005; Mauss 1992), "sistêmicas" (Malinowski 1986) e, mais recentemente, "densas" (Geertz 1989), "inteiriças" (Latour 1994) ou articuladoras entre "percepção -ação" (Ingold 2008). Mesmo diante da tese da "cultura" como "invenção" (Wagner 2010), a etnografia, vista aqui como instrumento criativo, teria o papel de construção de uma heurística plausível pautada pela materialização de "um padrão geral ou de um todo" (Wagner 2010).

Desse modo, a afinidade entre experiência etnográfica e discurso antropológico tem buscado de forma predominante a construção de narrativas articuladoras ou vinculantes das configurações observadas, independentemente do 
escopo e do refinamento teórico-metodológico predominante nas decorrências históricas da antropologia. Mesmo em iniciativas de negação da categoria "cultura" como uma propriedade totalizante, há o reconhecimento de que o procedimento etnográfico deve "primeiro apreender e depois apresentar" uma gama "de estruturas conceptuais complexas, muitas delas sobrepostas ou amarradas umas às outras" (Geertz 1989: 7).

Interessante, como bem se sabe, é que essa propriedade articuladora da etnografia não se apresenta per se, mas acompanhada de uma espécie de duplo reflexivo (termo usado aqui no sentido de autoconfrontação). Malinowski, por exemplo, confia que através da "compreensão de uma forma tão distante de natureza humana, possamos entender nossa própria natureza" (Malinowski 1976: 34). Assim como Lévi-Strauss, que afirma que "o observador coloca-se como seu próprio instrumento de observação [...], precisa aprender a conhecer-se, a obter de um si-mesmo, que se revela como outro ao en que o utiliza" (Lévi-Strauss 1993: 43-44). Mais recentemente, Descola explicou o efeito de sua experiência etnográfica como "uma espécie de ensimesmamento de efeitos paradoxais" (Descola 2006: 456), o que possibilitaria a capacidade de "fundar o conhecimento do outro sobre o desvendamento das próprias ilusões" (2006: 461).

Assim, ao possibilitar uma heurística configurada sobre e com o "outro" (seja ele o nativo melanésio ou o vizinho do bairro), abre-se a possibilidade de uma heurística do "eu", na qual o etnógrafo se entrega - de forma voluntária ou não - a uma reformulação interpretativa do seu próprio mundo. Essa "tensão entre heurísticas" tem sido identificada e, de certo modo, aclamada, dos clássicos aos contemporâneos. Dentre as diferentes formas contemporâneas de classificação dessa "tensão entre heurísticas", Viveiros de Castro tem trabalhado com a ideia de confrontação, ao afirmar que "fazer antropologia é comparar antropologias" (2004: 2). Essa perspectiva advoga um procedimento etnográfico pautado por uma equivalência radical entre as diferentes perspectivas, partindo do princípio que "nativos" formulam sua própria "tensão entre heurísticas". Etnografia, nessa perspectiva, poderia se tornar, não apenas o encontro entre duas heurísticas, mas o confronto entre duas formas de "tensão entre heurísticas" simétricas, mas diametralmente opostas.

Essas duas potencialidades metodológicas não seriam apreensíveis, no entanto, sem um processo de mobilização existencial que transcende as tentativas pretensamente objetivas ou objetivantes da análise. Esta premissa, também persistente na historicidade da reflexão antropológica sobre a etnografia, põe em destaque o que contemporaneamente tem-se convencionado denominar de "experiência etnográfica" (Lienhardt 1978; Goldman 2006; Magnani 2009). Tratada por Malinowski (1976: 20) como a "magia do etnógrafo", esta mobilização seria capaz de apreender do nativo a "essência de sua felicidade" (1976: 34), ou, de forma menos romântica, permitiria ao etnógrafo a possibilidade 
de "situar-se" de forma adequada para o "esforço intelectual" necessário para constituir-se a "inscrição" etnográfica (Geertz 1989). Mobilização intensa, na qual seria necessário ver-se "abandonado a um mundo onde tudo lhe é estrangeiro, frequentemente hostil", onde o etnógrafo "não tem senão este eu, [...] mas um eu física e moralmente abatido" (Lévi-Strauss 1993: 43-44). Nessa condição de fragilidade subjetiva é que a experiência etnográfica é possível, posto que ela "afetará seu curso, daí para diante" (Lévi-Strauss 1993: 43-44) em um processo de transição entre o olhar explicativo e compreensivo que permitiria o acesso à visão do outro, ou como diria a famosa ilustração de Geertz, "por sobre os ombros" do nativo (1989: 212).

Apesar de o posicionamento discursivo privilegiado do etnógrafo na situação etnográfica ter sido amplamente criticado nesta passagem de séculos (Clifford 2002; Castro 2002), a mobilização existencial do etnógrafo diante do nativo tem sido resguardada como fonte fundamental da produção etnográfica. O trabalho de Favret-Saada (2005) tem grande importância nesse processo. No contexto etnográfico, afetar-se ou permitir-se a afetividade seria o caminho fundamental para a produção de um entendimento pautado pela comunicação não intencional, não voluntária. A construção de uma experiência afetiva do etnógrafo, sem buscar apreender a experiência dos nativos - "os tambores do antropólogo..." (Goldman 2008, grifo nosso) - e, portanto, sem a pretensão de colocar-se por detrás dos ombros de ninguém, se constituiria no ponto de partida para a posterior manufatura da compreensão e inscrição etnográfica.

Esse posicionamento amplamente aceito remete à tentativa de dissipar na narrativa antropológica a tensão do entendimento dos discursos nativos como "crença" ou, de forma oposta, como "verdade outra", ambas vistas como expressões do universalismo e do relativismo. Com a "afetação", teríamos um recurso de confronto de perspectivas em condição de equivalência conceitual sobre os territórios existenciais colocados em confronto na experiência etnográfica (Goldman 2008).

\section{Rumo à alteridade paisagística}

Os contornos acima colocados nos possibilitam vislumbrar três contribuições da etnografia aos processos de produção de conhecimento em ambientes de alteridade, mesmo aqueles não classicamente considerados etnográficos, como é o caso aqui descrito: (1) construção de narrativas articuladoras ou vinculantes, (2) produzidas na "tensão entre heurísticas" e (3) possibilitadas pela mobilização existencial da experiência etnográfica. É interessante notar que o esforço de promover a equivalência entre as perspectivas a partir de um modelo de uso e cobertura da terra parece ter nos aproximado de forma bastante rica aos três elementos etnográficos acima descritos.

Primeiro, longe de aferir uma "totalidade", nossa pesquisa estimulou a produção de nuances articuladoras potencialmente presentes no modo de vida das 
famílias agricultoras, tanto no que se refere aos pressupostos motivadores da investigação, quanto pelo tipo de mobilização existencial experimentada pelos agentes. Tal como observado no exemplo da situação de pesquisa no lote de D. Maria, a transposição horizontal/vertical colocou em evidência a tessitura da paisagem a partir de procedimentos de associação entre momento/forma de uso/ocupação e situação/organização familiar. A manufatura das narrativas articuladas emergiu em estreita afinidade com o modo em que a interação foi situada no contexto de pesquisa.

Ou seja, o desafio metodológico de conceber a produção de sua paisagem nos limites necessários à futura sobreposição entre croquis e imagens levou os produtores rurais a usar estas últimas como ponto de partida para a transposição, não no sentido de uma "inspiração", mas como uma matriz de inteligibilidade para a verticalização. Essa dinâmica potencializou o debate intrafamiliar - ou a autorreflexão do respondente solitário - em torno da distribuição dos polígonos sobre a estruturação predefinida do croqui, exigindo, portanto, um esforço de correlação entre o desenho e a configuração sócio-histórica. Isso inviabiliza uma visão de "totalidade" sobre a "cultura" dos agricultores, pois o que dela emerge refere-se ao que foi estimulado pela confecção do desenho. Por outro lado, fomenta "transversais ontológicos" parciais, mobilizados pelo (re)configurar da paisagem em outros termos.

Em segundo lugar, a experiência de pesquisa nos permitiu conceber o termo "tensão" a partir de um processo de encadeamento instável entre o estranhamento e a aproximação no processo de formação das heurísticas. Essa tensão indica que a relação comunicativa não se constituiu primeiro por uma situação "pura" de estranhamento, para depois encontrar-se definitivamente com a aproximação, mas, antes, como um processo de "relutância" no qual o estranhamento manteve-se entremeado pelas fissuras reveladoras sobre a atuação do outro. Artefato tecnológico distante do cotidiano daquelas famílias, a imagem de satélite produziu, constantemente, uma intrigante sensação de "fascínio" e "receio". Na interface entre as duas, nasceu o estímulo de produzir a própria categorização espacial.

Em terceiro lugar, entendemos que a mobilização existencial fundante da experiência etnográfica não se encontrou em separado do processo mais geral da atividade investigativa dita científica, posto que ela não se apresentou dissociada da aplicação das metodologias de pesquisa e da atitude dialogada do pesquisador sobre e com o nativo. Em outros termos: a aplicação de técnicas de investigação próprias de estudos sobre uso e cobertura da terra não inviabilizou as inserções etnográficas produzidas pela situação de campo. Nosso entendimento é que elas, ao contrário, potencializam essas inserções. Assim, diferentemente da perspectiva da afetação (Favret-Saada 2005, 1977) e seu modelo schize de dissociação entre as dimensões afetiva e intelectiva do entendimento etnográfico, verificamos que estas técnicas incitaram uma certa 
disposição entre comunicação voluntária e involuntária, produzidas em um mesmo ato de interlocução.

A emergência de dinâmicas de alteridade concernentes ao olhar etnográfico em pesquisas comumente pensadas como "convencionais" abre espaço para pensarmos a dimensão afetiva de forma indissociável ou, pelo menos, plenamente articulável com a dimensão intelectiva, tanto na heurística do pesquisador quanto na do nativo. Assumindo o pressuposto fundamental de que "os procedimentos que caracterizam a investigação são conceitualmente da mesma ordem que os procedimentos investigados" (Castro 2002) e que, como sugerimos, não houve dissociação entre aspectos afetivos e intelectivos, é necessário reconhecer que o outro, posto em situação etnográfica, também não promoveu a dissociação entre afetividade e intelectividade. Nestes termos, a curiosidade se apresentou como um dado comum na experiência etnográfica e envolveu, de ambas as partes, atitudes "cientes" e "não cientes", "calculadas" e "não calculadas” de apreensão do outro.

Essas três considerações nos remetem a um terreno favorável de resposta às questões produzidas no âmbito da pesquisa, a saber: como se deu a transposição horizontal/vertical sem desperdício da densidade sócio-histórica? Como se deu a diversidade classificatória? E em que condições se retém, no âmbito da classificação, os estratos de paisagem não apreensíveis à imagem de satélite?

\section{Entre horizontalidade e verticalidade, o olhar diagonal em movimento}

Parte-se aqui do reconhecimento de que a transposição "chão-alto" se constituiu no contexto radicalmente interacional proporcionado pela pesquisa. Se produzidos por interação, estaríamos, então, longe da ideia de que os croquis foram expressões de "mapas cognitivos" nos quais o reconhecimento do ambiente se realizou através da reprodução de uma estrutura complexa - a paisagem - no "aparelho cognitivo" do nativo. Antes, se constituem como frutos do processo de "unfolding of a field of relations established through the immersion of the actor-perceiver within a given environmental context" (Ingold 2000: 220). Nada há de preestabelecido em termos de "saber" nativo sobre uma perspectiva verticalizada, mas, sim, um processo operacionalizante de produção inventiva (Wagner 2010) e articuladora entre o "voo de pássaro" (Turnbull 2000) e o "descobrir-caminho" (Ingold 2005). A utilização destes conceitos nos interessa, não apenas pela caracterização imagética da verticalidade e da horizontalidade que eles oferecem, mas pelo seu aspecto dinâmico: o voar e o caminhar. Articulados, eles produzem uma "perspectiva diagonal em movimento" como forma de caracterizar o ponto de vista nativo na confecção dos croquis.

Essa interseção permite o entendimento de que o posicionamento de cada polígono e sua consequente classificação foram produzidos a partir da indexação dos fragmentos experienciais de uso da - e atuação na - terra (a densidade 
sócio-histórica), e colocados "em elevação" em direção à referência possibilitada pela imagem de satélite. No exercício imaginativo dos agricultores e agricultoras se estabeleceu um movimento tensional entre os pontos referenciais disponíveis de horizontalidade e verticalidade. A título de ilustração, esta perspectiva diagonal seria algo como o que poderia ser produzido pelo olhar de um tripulante durante a decolagem de um balão. Para cada croqui produzido, muitas "decolagens" teriam sido realizadas pelos agricultores.

Finalmente, a ideia de um olhar diagonal possibilita-nos compreender de que modo os agricultores e agricultoras se lançavam à busca da verticalidade, sem abrir mão da experiência produzida no chão. O exercício de posicionar um polígono representativo de uma área de uso com determinada cobertura implicava, portanto, no procedimento de buscar na memória um acontecimento "marcador" que possibilitasse a transposição à verticalidade. A classificação, então, prosseguia com outros polígonos colocados em relação ao primeiramente identificado ou a outros acontecimentos marcadores. Esses procedimentos possibilitaram a produção de um número expressivo de classificações, justamente porque a marcação por acontecimentos estava plenamente articulada à diversidade dos usos. Esse é o mesmo procedimento que gera a identificação minuciosa dos estratos médios de cobertura, levando-se em consideração que é nesses estratos que se abriga a maior diversidade de usos.

\section{PARA COLHER OS FRUTOS}

Três conjuntos de contribuições podem ser vislumbradas deste estudo. Quanto ao primeiro conjunto, (1) observamos que a sobreposição de imagens e croquis, além de oferecer diferentes graus de entendimento das formas de uso e ocupação da terra, sugere que a participação da perspectiva nativa está para além da validação da imagem produzida pelo olhar tecnocientífico, ou seja, são perspectivas diferentes, mas igualmente válidas para as análises de UCT. Isto, porque (2) o percentual de correspondências esperadas e aceitáveis coloca croquis e imagens em um mesmo nível de capacidade de definição e classificação da representação espacial dos lotes. No entanto, (3) demonstrámos que parte significativa das discrepâncias entre os dois recursos imagéticos deriva não somente de "erros" diversos, mas sobretudo do fato de as imagens de satélite não apreenderem pequenas dimensões de uso e estratos médios de cobertura, justamente onde os desenhos apresentaram acuidade definitória e diversidade classificatória com relação à paisagem dos lotes.

Quanto ao segundo conjunto de contribuições, (1) partimos da consideração de que a abordagem etnográfica se constitui por três elementos fundamentais, dentre outros possíveis: a narrativa articuladora ou vinculante; a tensão entre heurísticas; e a mobilização existencial dos entes em interação. A partir daí (2) inferimos que, em nossa pesquisa, produziram-se "transversais 
ontológicos" articuladores de acontecimentos rememorados e disposições de espacialidade. Do mesmo modo, (3) a "tensão entre heurísticas" produzida na pesquisa emergiu da relutância entre estranhamento e aproximação, na qual o desconforto perante outrem e o esforço de concebê-lo como "válido" estiveram constantemente presentes. Nesse sentido, (4) a mobilização existencial manifestou-se como uma atuação articulada entre afetividade e intelectividade, o que nos possibilitou problematizar a tendência favret-saadaniana de dissociação entre os termos no estatuto etnográfico. E, por fim, (5) a constatação de que estes elementos etnográficos nasceram de uma pesquisa não "propriamente" etnográfica.

Estes aportes nos levam a um terceiro conjunto de contribuições: (1) longe de evidenciar um suposto "mapa cognitivo", insistimos que os croquis expressaram uma heurística espacializada produzida na situação de pesquisa, sendo, portanto, produto da alteridade dos seus entes constitutivos - agricultores, técnicos, cientistas, mapas, croquis e imagens de satélite. Nesse processo, (2) a interseção "chão-alto" produziu o que denominamos "perspectiva diagonal em movimento", possibilitada, metaforicamente, ao tripulante em uma "decolagem de balão". Essa caracterização possibilitou (3) o entendimento de que o esforço de transição entre horizontalidade e verticalidade conserva a densidade sócio-histórica porque não reproduz uma verticalidade "pura", mas sim um olhar aquém e além das duas referências iniciais. Fruto desse movimento, (4) a diversidade classificatória expressa nos croquis foi possível pois a heurística diagonal possibilitaria várias "decolagens" para a produção de um mesmo desenho. Verificamos ainda (5) a manutenção da cuidadosa identificação dos "estratos médios" pela perspectiva diagonal, pouco apreensível pela verticalidade distante da imagem de satélite.

Finalmente, ao sugerirmos uma certa etnografia na interseccionalidade afetivo-intelectiva, desejamos olhar para a potencialidade epistêmica da convivência do fazer etnográfico com outras expressões metodológicas, tanto no sentido de atravessar o curso destas últimas, quanto de se deixar permear por elas. Evidentemente, isso nos impele à problematização da ideia de que a descrição e a experiência etnográficas devem se constituir como "puras" e estritamente afinadas à expertise antropológica. Se tanto etnografia quanto antropologia têm alcançado êxito no seu esforço de "dissolução das fronteiras" ontológicas, parece-nos pertinente agir para que isto tenha reverberação na própria episteme etnográfica. 


\section{BIBLIOGRAFIA}

ALMEIDA, Alfredo Wagner Berno de, 2013, "Nova cartografia social da Amazônia", em A.W.B. de Almeida e E.A. Farias Júnior (orgs.), Povos e Comunidades Tradicionais: Nova Cartografia Social. Manaus, UEA Edições.

BATISTEllA, Mateus, Emilio F. MORAN, e Diogenes Salas ALVES (orgs.), 2008, Amazônia: Natureza e Sociedade em Transformação. São Paulo, SP, Editora da Universidade de São Paulo.

BROWDER, J.O., R.H. WYNNE, e M.A. PEDLOWSKI, 2005, "Agroforestry diffusion and secondary forest regeneration in the Brazilian Amazon: further findings from the Rondonia Agroforestry Pilot Project (1992-2002)", Agroforestry Systems, 65: 99- 111.

CASTRO, Eduardo Viveiros de, 2002, "O nativo relativo", Mana, 8 (1): 113-148.

CASTRO, Eduardo Viveiros de, 2004, "Perspectival Anthropology and the method of controlled equivocation", Tipití: Journal of the Society for the Anthropology of Lowland South America, 2 (1): \# 1.

CASTRO, Fábio de, et al., 2002, "The use of remotely sensed data in rapid rural assessment", Field Methods, 14 (3): 243-269.

CLIFFORD, James, 2002, A Experiência Etnográfica: Antropologia e Literatura no Século XX. Rio de Janeiro, EdUFRJ.

D’AnTONA, Álvaro de O., Anthony D. CAK, e Leah VANWEY, 2008, “Collecting sketch maps to understand property land use and land cover in large surveys", Field Methods, 20: 66-84.

D’ANTONA, Álvaro de O., Anthony D. CAK, e Thais T. NASCIMENTO, 2008, "Integrando desenhos e imagens de satélite no estudo de mudanças no uso e cobertura da terra", Ambiente e Sociedade, 11: 99-116.

D’AnTOnA, Álvaro de Oliveira, Anthony D. CAK, e Roberto D. SILVA JÚNIOR, 2011 , "Distant versus local: assessing two perspectives of land use and land cover for sustainability assessment of rural areas of the Amazon", em The XVIIIth International Conference of the Society for Human Ecology, 2011, Lake Las Vegas, NV. Conference Abstracts, 46-47.

DESCOLA, Phillipe, 2006, As Lanças do Crepúsculo: Relações Jivaro na Alta Amazônia. São Paulo, Cosac Naify.

FAVRET-SAADA, Jeanne, 1977, Les Mots, la Mort, les Sorts. Paris, Gallimard.

FAVRET-SAADA, Jeanne, 2005, "Ser afetado", Cadernos de Campo, 13: 155-161.

FISHER, P., A. COMBER, e R. WADSWORTH, 2005, "Land use and land cover: contradiction or complement”, em P. Fisher e D. Unwin (orgs.), Re-presenting GIS. Chichester, John Wiley \& Sons.

FLORÊNCIO, Fernando, 2012, "Diálogos entre textos e contextos etnográficos", Etnográfica, 16 (3): 619-624, disponível em < https://etnografica.revues.org/2136> (última consulta em outubro de 2016).

GEERTZ, Clifford, 1989, A Interpretação das Culturas. Rio de Janeiro, Livros Técnicos e Científicos Editora.

GOLDMAN, Marcio, 2006, "Alteridade e experiência: antropologia e teoria etnográfica", Etnográfica, 10 (1): 161-173, disponível em < http://www.scielo.mec.pt/scielo.php?scrip$\mathrm{t}=$ sci_arttext\&pid=S0873-65612006000100008 > (última consulta em outubro de 2016). 
GOLDMAN, Marcio, 2008, “Os tambores do antropólogo: antropologia pós-social e etnografia", Ponto Urbe, 3: 1-11.

INGOLD, Tim, 2000, The Perception of the Environment: Essays on the Livelihood, Dwelling and Skill. Londres e Nova Iorque, Routledge.

INGOLD, Tim, 2005, "Jornada ao longo de um caminho de vida: mapas, descobridor-caminho e navegação”, Religião e Sociedade, 26 (1): 76-110.

INGOLD, Tim, 2008, "Anthropology is not ethnography", Proceedings of the British Academy, 154: 69-92.

LATOUR, Bruno, 1994, Jamais Fomos Modernos: Ensaio de Antropologia Simétrica. Rio de Janeiro, Editora 34.

LÉVI-STRAUSS, Claude, 1993, Antropologia Estrutural II. Rio de Janeiro, Tempo Brasileiro.

LIENHARDT, Godfrey, 1978, Divinity and Experience: The Religion of the Dinka. Oxford, Clarendon Press.

LOMBARDI, Thais Tartalha do Nascimento, 2013, "Os colonos e os daqui: trajetórias e paisagens ao longo da Rodovia Transamazônica”, em E.P. Godoi e M.A. Menezes (orgs.), Uma Terra para Se Viver: Assentados, Colonos e Quilombolas. São Paulo/Brasília, Annablume/CNPq.

MAGNANI, José Guilherme Cantor, 2009, "Etnografia como prática e experiência”, Horizontes Antropológicos, 15 (32): 129-156.

MALINOWSKI, Bronislaw, 1976, Argonautas do Pacífico Ocidental: Um Relato do Empreendimento e da Aventura dos Nativos nos Arquipélagos da Nova Guiné, Melanésia. São Paulo, Abril Cultural.

MALINOWSKI, Bronislaw, 1986, “A teoria funcional”, em E. Durham (org.), Malinowski. São Paulo, Ática, 169-188.

MAUSS, Marcel, 1992, Sociologia e Antropologia. São Paulo, Editora Pedagógica Universitária/EdUSP.

McCRACKEN, Stephen D., et al., 1999, "Remote sensing and GIS at farm property level: demography and deforestation in the Brazilian Amazon", Photogrammetric Engineering and Remote Sensing, 65 (11): $1311-1320$.

MORAN, Emilio F., 1981, Developing the Amazon. Bloomington, IN, Indiana University Press.

MORAN, Emilio F., et al., 1994, "Integrating Amazonian vegetation, land-use, and satellite data", Bioscience, 44: 329-338.

MORAN, Emilio F., e Eduardo S. BRONDIZIO, 1998, "Land-use change after deforestation in Amazonia", em D. Liverman et al. (orgs.), People and Pixels: Linking Remote Sensing and Social Science. Washington, DC, National Academy Press, 94-120.

RINDFUSS, R. R., e P.C. STERN, 1998, “Linking remote sensing and social science: the need and the challenges”, em D. Liverman et al. (orgs.), People and Pixels: Linking Remote Sensing and Social Science. Washington, DC, National Academy Press, 1-27.

ROMNEY, A., S. KIMBALL, e W.H. BATCHELDER, 1987, "Culture and consensus: a theory of culture and informant accuracy", American Anthropologist, 88: 313-338.

SCHROTH, G., et al., 2001, "Plant-soil interactions in multistrata agroforestry in the humid tropics", Agroforestry Systems, 53: 85-102.

TURnBUlL, David, 2000, Masons, Tricksters and Cartographers: Comparative Studies in the Sociology of Scientific and Indigenous Knowledge. Londres, Routledge.

TYLOR, Eduard Burnett, 2005, "A ciência da cultura", em C. Castro (org.), Evolucionismo Cultural: Textos de Morgan, Tylor e Frazer. Rio de Janeiro, Jorge Zahar Editor. 
VANWEY, Leah K., Álvaro de O. D’ANTONA, e Eduardo S. BRONDIZIO, 2007, “Household demographic change and land use/land cover change in the Brazilian Amazon", Population and Environment, 28 (3): 163-185.

WAGNer, Roy, 2010, A Invenção da Cultura. São Paulo, Cosac Naify. 